\title{
Interpretações de Nestor dos Santos Lima sobre a docência em instituições profissionais brasileiras e argentinas (1923)
}

Nestor dos Santos Lima's interpretations on teaching in Brazilian and Argentine professional institutions (1923)

Interpretaciones de Nestor dos Santos Lima sobre la docencia en instituciones profesionales brasileñas y argentinas (1923)

\author{
SARA RAPHAELA MACHADO DE AMORIM
}

Francinaide de Lima Silva Nascimento (iDb

RAQuel Lopes PIREs (iDc

\section{Resumo}

O presente artigo busca analisar interpretações, produzidas pelo dirigente educacional norte-rio-grandense Nestor dos Santos Lima, sobre a docência em instituições de educação. Comissionado oficialmente no ano de 1923 para observar espaços educacionais em estados brasileiros e na região do Rio da Prata, produziu um minucioso registro contendo dados e impressões acerca dos espaços visitados e que permitem perspectivar as relações entre os saberes e práticas que orientavam a docência desenvolvida no Brasil e na Argentina no respectivo período. Esta investigação centra-se, portanto, no conhecimento das ideias e práticas que circularam internacionalmente a partir da intersecção entre os países analisados. Em termos teórico-metodológicos, fundamenta-se na História Cultural e nos elementos da História Comparada, bem como na História da Educação Profissional,

\footnotetext{
a Universidade do Estado do Rio Grande do Norte (UERN), Natal, RN, Brasil. Doutora em Educação, e-mail: saraamorim@uern.br

b Instituto Federal de Educação, Ciência e Tecnologia do Rio Grande do Norte (IFRN), Natal, RN, Brasil. Doutora em Educação, e-mail: francinaide.silva@ifrn.gov.br

c Universidade Federal do Rio de Janeiro (UFRJ), Rio de Janeiro, RJ, Brasil. Mestre em Educação, e-mail: rlopes.pires@gmail.com
} 
numa perspectiva transnacional. Dessa forma, são interlocutores Ciavatta (2007; 2009), Cunha (2005), Chartier (1990), Catani (2007), Roldán Vera e Fuchs (2021), Riondet, Hofstetter e Go (2018), dentre outros. A análise do relatório ressalta o contato do dirigente com a Associação Brasileira de Educação e demais sujeitos que circulavam no país. No tocante à educação para o trabalho, destaca-se a crescente procura por qualificação em um ofício com a aquisição do conhecimento prático, conferindo uma visão técnica e artística. Nesse sentido, as visitas comissionadas buscaram imprimir cientificidade e significação social às formações para o progresso técnico nas oficinas e nas indústrias nacionais.

Palavras-chave: História da Educação Profissional. História Transnacional. Saberes e Práticas.

\section{Abstract}

This work aims to analyze interpretations regarding teaching in educational institutions made by the educational leader Nestor dos Santos Lima from Rio Grande do Norte in Brazil. Nestor Lima was officially commissioned in 1923 to observe educational institutions in Brazilian states and in the Rio da Prata region. In this realm, he produced a meticulous record containing data and impressions regarding the schools he visited that allowed to acknowledge the perspective of the relationships between knowledge and educational practices developed in Brazil and Argentina in this period. Thus, this work deals with knowledge of ideas and practices that occurred internationally in the forementioned countries. In theoretical-methodological terms, the research is based on Cultural History and on elements of Comparative History, as well as on the History of Professional Education, in a transnational perspective. Thus, Ciavatta (2007; 2009), Cunha (2005), Chartier (1990), Catani (2007), Roldán Vera and Fuchs (2021), Riondet, Hofstetter as well as Go (2018), among others were considered. The report analysis highlights the director's contact with the Brazilian Association of Education and other people in the country. With regard to education for labour, there is a growing demand for qualification in a trade with the acquisition of practical knowledge, providing a technical and artistic vision. In this sense, the commissioned visits sought to imprint scientific and social significance to training for technical progress in workshops and in national industries.

Keywords: History of Professional Education. Transnational History. Knowledge and Practices.

\section{Resumen}

Este artículo busca analizar las interpretaciones producidas por el dirigente educacional Nestor dos Santos Lima, sobre la docencia en instituciones de educación. Encargado oficialmente en el año de 1923 de observar espacios educacionales en estados brasileños y en la región del Río de la Plata, produjo un minucioso registro conteniendo datos e impresiones acerca de los espacios visitados que permite una perspectiva de las relaciones entre los saberes y prácticas que guiaron la docencia desarrollada en Brasil y 
en Argentina en el respectivo período. Esta investigación se centra, por lo tanto, en el conocimiento de las ideas y prácticas que circularon internacionalmente desde la intersección entre los países analizados. En términos teórico-metodológicos, se basa en la Historia Cultural y en los elementos de la Historia Comparada, así como en la Historia de la Educación Profesional, en una perspectiva transnacional. Así, los interlocutores son Ciavatta (2007; 2009), Cunha (2005), Chartier (1990), Catani (2007), Roldán Vera e Fuchs (2021), Riondet, Hofstetter e Go (2018), entre otros. El análisis del informe destaca el contacto del dirigente con la Asociación Brasileña de Educación y otros actores que circularon en el país. Con respecto a la educación para el trabajo, destaca la creciente demanda de cualificación en un oficio con la adquisición de conocimiento práctico, proporcionando una visión técnica y artística. En este sentido, las visitas realizadas buscaron darle cientificidad y trascendencia social a la formación para el progreso técnico en los talleres y en las industrias nacionales.

Palabras clave: Historia de la Educación Profesional. Historia Transnacional. Saberes y Prácticas.

\section{Introdução}

No acervo do Instituto Histórico e Geográfico do Rio Grande do Norte (IHGRN), localizamos a fonte documental que motivou a observação de singularidades históricas da docência na educação profissional dos países que se constituem enquanto foco da nossa investigação. No ano de 1923, após ser comissionado para observar o ensino na Argentina, Uruguai e nos estados do sul e sudeste do Brasil, Nestor dos Santos Lima, então Diretor da Instrução Pública do Rio Grande do Norte, produziu um relatório de viagem constituído por distintas seções, organizadas de acordo com os destinos e espaços visitados. Nesses lugares, além de descrever suas impressões, reflexões e críticas em torno das realidades experimentadas, elaborou apreciações sobre as instituições averiguadas, como também acerca dos saberes e fazeres docentes, contextualizando-os de modo mais amplo no diálogo com os programas de ensino, reformas escolares e a legislação educacional vigente em cada diferente localidade. Desse modo, o artigo insere-se no campo da História da Educação Profissional (CUNHA, 2005; CIAVATTA, 2007; 2009) ao propor-se a analisar interpretações acerca da docência desenvolvida em instituições de educação profissional, a partir do manuscrito "Da organização do ensino normal, profissional e primário no sul do Brasil e no Rio da Prata" (1923), de autoria do referido educador e dirigente norte-rio-grandense. 
$\mathrm{Na}$ escrita do preâmbulo do relatório o autor sinalizou as intenções que subsidiaram o planejamento do trânsito, quando se dirigiu ao então governador do estado Antônio José de Mello e Souza, de quem recebeu a supracitada atribuição profissional:

Do desempenho da comissão que, por acto de 3 de março deste anno [1923], dignou-se V. Exc. de incumbir-me para observar, no Sul do Paiz, a organização do ensino normal e profissional, a qual resolvi ampliar para abranger o ensino primário também, nas Republicas Oriental e Argentina, tenho a honra de trazer, nas linhas que seguem, um relatório singelo, mas, circunstanciado, afim de que V. Exc. possa inferir na situação daquelles serviços os proveitos, que, porventura, resultam dessa comissão, em prol da nossa organização escolar (LIMA, 1923, p. 3-4, grifo nosso).

Embora tenha percorrido diversas instituições educacionais nos três países pelos quais circulou, neste estudo é estabelecido um recorte que compreende apenas os espaços visitados no Brasil (São Paulo, Minas Gerais e Rio de Janeiro) e na Argentina, o que se justifica pelo fato de que apenas nessas localidades o educador observou o que ele mesmo classificou enquanto escolas de formação profissional. A partir das reflexões acerca das ideias e práticas registradas na fonte histórica analisada, são prescrutados aspectos relacionados à docência desenvolvida nas instituições que foram objeto de conhecimento de Nestor dos Santos Lima.

Com larga atuação na educação pública do Rio Grande do Norte, o referido educador já havia vivenciado a observação do que designou como "centros de maior cultura pedagógica do país" (LIMA, 1913, p. 3-4), ao viajar no ano de 1913 para conhecer de perto a educação que se desenvolvia nos estados de São Paulo e Rio de Janeiro. No período entre a realização de suas duas viagens, esteve à frente da direção da Escola Normal de Natal (1911-1923), despedindo-se deste posto apenas quando passou a assumir a direção da Instrução Pública durante o período de 1924 a 1928.

Dentre os aspectos que merecem destaque em relação à sua atuação intelectual, ressaltamos a ocupação na presidência do IHGRN no decurso de trinta e dois anos, o que o fez ser considerado presidente perpétuo dessa casa da memória. Acentuamos, ainda, o fato de ter sido ele um dos fundadores da Academia Norte-Rio-Grandense de Letras (ANRL), na qual atuou como secretário geral e, posteriormente, tornandose imortal, com a ocupação da cadeira de número 9. No cenário nacional, fez-se presente nos diálogos desenvolvidos pela Associação Brasileira de Educação (ABE) e trabalhou como sócio correspondente no Instituto Histórico e Geográfico Brasileiro 
(IHGB). No âmbito da educação estadual produziu documentos institucionais oficiais, a exemplo dos Regimentos Escolares e Relatórios do Departamento de Educação, bem como disseminou suas reflexões e experiências por meio de impressos como a Revista Pedagogium e o jornal $A$ República².

Para esta pesquisa, em acordo com a temática abordada, elegemos para análise o relatório de viagem que exprime suas impressões e ideias acerca do ensino profissional. Destacamos que para o trabalho de investigação com essa fonte documental é necessária a compreensão de que a realidade observada é fruto de escolhas e objetivos específicos que jamais a permitiriam ser vista de forma neutra. Por essa razão, “[...] exige certo cuidado por se tratar de um texto ideologizado; traz um discurso pedagógico que, por natureza, é político-ideológico, ou seja, uma verdade na pretensão de estabelecê-la. É persuasivo, retórico, prescritivo, autoritário e orientador de uma prática" (CARDOSO; MORAES, 2014, p. 20). Constitui-se enquanto produto de uma viagem pedagógica, que, por sua vez, é considerada por José Gonçalves Gondra (2007) como possibilidade de suprir as limitações por vezes impostas pelos materiais impressos. Segundo o autor, tais viagens emergiram como "recomendação metodológica e como complemento do esforço para compreender o estrangeiro" (GONDRA, 2007, p. 65, grifo do autor), seus caminhos, fazeres, saberes e decifrações educacionais para situações semelhantes enfrentadas nas mais diferentes localidades, fossem estas nacionais ou internacionais.

O trabalho com fontes históricas resultantes de viagens pedagógicas permite que os pesquisadores do campo da História da Educação observem determinados episódios, a partir dos olhares e escritos de outros educadores do passado, percebendo suas motivações, entendimentos, questionamentos e compreensões.

Uma vez que o historiador trabalha com sociedades que já desapareceram ou se transmutaram - ou, mais ainda, com processos que já se extinguiram ou que fluíram

1 Criada pela Associação de Professores do Rio Grande do Norte (APRN), a Revista Pedagogium teve sua primeira edição publicada no ano de 1921 e foi um dos principais periódicos de divulgação educacional no estado do Rio Grande do Norte. Sobre este assunto consultar: Ribeiro (2020).

2 Fundado no ano de 1889 pelo primeiro governador do Rio Grande do Norte, Pedro Velho de Albuquerque Maranhão, constituiu-se como um dos principais veículos de informação no território potiguar. Sobre este assunto consultar: Costa (2005). 
através de transformações que terminaram por atravessar os tempos até chegar ao presente produzindo novos efeitos - não existiria outro modo de perceber estas sociedades ou apreender estes processos senão a partir das chamadas "fontes históricas", aqui entendidas como os diversos resíduos, vestígios, discursos e materiais de vários tipos que, deixados pelos seres humanos historicamente situados no passado, chegaram ao tempo presente através de caminhos diversos (BARROS, 2019, p. 7).

A complexidade de estudo dos fenômenos educativos exige uma investigação que ultrapasse os limites de compreensão restritos às instituições e seus agentes. Portanto, para perspectivar as relações entre a docência na educação profissional desenvolvida no Brasil e na Argentina, em perspectiva comparada corroborando Catani (2007), fundamentamo-nos na História Cultural (CHARTIER, 1990), corroborados, também, pelo entendimento de que o "[...] estudo da produção de sentidos sobre o mundo construído pelos homens do passado sinaliza para uma compreensão dos diferentes processos educativos e escolares" (STEPHANOU; BASTOS, 2018, p. 418). Outrossim, respalda-se na categoria Trabalho-Educação mobilizada por Ciavatta (2009) que compreende o sentido amplo da educação profissional e sua historicidade, na qual incluem-se os espaços de formação docente, tais quais os visitados pelo educador.

É relevante destacar que na construção deste estudo trabalhamos a partir da perspectiva de História Transnacional, em diálogo com Roldán Vera e Fuchs (2021, p. 8), por compreendermos que "embora também se refira a uma história que atravessa fronteiras [...] não desconstrói a nação [...] mas contextualiza-a em um conjunto de relações de tradução, entrelaçamentos e dependências". Portanto, perseguimos por meio das interpretações de Nestor Lima em seus deslocamentos pelo Brasil e Argentina, iniciativas relacionadas à docência nas instituições de educação profissional, observando as circulações e conexões entre ideias, sujeitos e projetos.

\section{Destinos, observações e compreensões}

A partir do mapeamento, interpretação e análise dos dados obtidos no relatório de viagem "Da organização do ensino normal, profissional e primário no sul do Brasil e no Rio da Prata" (1923), são perscrutados não somente aspectos referentes às instituições visitadas e seus projetos educacionais, mas, também, as noções acerca 
da docência na educação profissional construídas pelo autor do documento. Tais elementos são observados em diálogo com outras tipologias documentais, a exemplo da fotografia que contribui para a fundamentação e explicitação das informações veiculadas na construção do estudo.

Pressupomos que a compreensão dos intuitos que orientaram o trânsito realizado por Nestor dos Santos Lima, parte desde os caminhos percorridos até as aspirações que nutriu durante seu período de atuação profissional à frente da educação no Rio Grande do Norte. Acreditamos que a missão comissionada teve seu planejamento embasado tanto nas preocupações em torno de sua gestão na principal instituição de formação docente no estado, a Escola Normal de Natal, quanto pela busca de conhecimentos subsidiadores para o projeto que efetivaria ao assumir a pasta da educação pública no território potiguar no ano posterior à viagem.

Perscrutar os itinerários do educador nessa incursão pelos países permite-nos uma análise biográfica e da sua atuação profissional, como também amplia a compreensão acerca do movimento histórico de constituição do ideário pedagógico vigente. Corroboramos, portanto, a compreensão de Riondet, Hofstetter e Go (2018, p. 13), os quais afirmam que apreender "itinerários permite evitar dois extremos: a focalização biográfica de personagens panteões em detrimento da história e sociologização da história raramente do indivíduo para o coletivo. O desafio é situar o autor ao seu lugar sem fazer dele um átomo social ou uma exceção"3. De acordo com os autores, estudar percursos impõe dois trabalhos: o de singularizar diversas pedagogias conhecidas e o de identificar os fenômenos de subjugação e recuperação, do momento ou da pedagogia em curso.

É neste sentido que um itinerário difere de uma biografia: busca um equilíbrio entre o ator e os grupos sociais que frequenta, o que possibilita observar como o pensamento em jogo se expressa e se desenvolve, corporificado em práticas ou sistemas concretos. Isso ajuda não a cair nas derivas de uma mitologia, mas sim a poder progredir no conhecimento do pensamento, das práticas e das representações de um pedagogo (RIONDET; HOFSTETTER; GO, 2018, p. 182).

Diante dessa compreensão, examinamos Nestor dos Santos Lima enquanto um homem do seu tempo em relação aos outros dirigentes da educação do período,

\footnotetext{
${ }^{3}$ Todas as traduções são de nossa autoria.
} 
os quais também estiveram em trânsito pela constituição de projetos educacionais semelhantes. Cientes de que a viagem do educador potiguar não foi uma ação isolada, exploramos seus sentidos, atentando para as razões que o fizeram ser o indivíduo indicado para tal missão, bem como a ocupação de espaços que o permitiram construir as redes de contatos que o conduziram a cada novo lugar.

Após viajar a bordo do transatlântico alemão "Cap. Polônio", Nestor Lima desembarcou na noite de 02 de maio de 1923 em seu destino inicial, Montevidéu. Após a primeira parada internacional, seguiu para Buenos Aires, capital da Argentina, e finalizou sua viagem retornando à terra natal pelos seguintes estados brasileiros: São Paulo, Minas Gerais, Rio de Janeiro e Espírito Santo. A partir do quadro a seguir, é possível visualizar as instituições visitadas em cada localidade:

Quadro 1 - Destinos e instituições visitadas pela comissão norte-rio-grandense

\begin{tabular}{|l|l|}
\hline LOCALIDADES & \multicolumn{1}{|c|}{ INSTITUIÇÕES } \\
\hline \multirow{5}{*}{ MONTEVIDÉU } & Escuela Normal para Niñas \\
& Escuela Práctica para Candidatos Nacionales \\
& Escuela de $2^{\circ}$ grado n. 22 \\
& Escuela de Aplicación para Niñas \\
& Escuela de Aplicación para Varones \\
& Escolas especiais: Instituto Nacional de Niñas Surdo-Mudas \\
& Escuela al Aire Libre \\
& Escuela de Práctica n. 14 de Primer Grado \\
\hline \multirow{5}{*}{ BUENOS AIRES } & Escuela General San Martin \\
& Escuela Estados Unidos del Brasil \\
& Escuela Normal de Varones \\
& Escuela de Aplicación \\
& Escuelas Complementarias \\
\hline \multirow{5}{*}{ SÃO PAULO } & Escola Normal da Praça da República \\
& Escola Normal do Braz \\
& Escolas Complementares \\
& Grupo Escolar Rodrigues Alves \\
& Grupo Escolar do Carmo \\
& Escola Reunida de São Bernardo \\
& $1^{\circ}$ Grupo Escolar de Santo André \\
& $2^{\circ}$ Grupo Escolar de Santo André \\
& Escola Profissional Feminina \\
& Escola Profissional Masculina \\
& Faculdade de Pedologia \\
\hline
\end{tabular}

(Continua)

Quadro 1 - Destinos e instituições visitadas pela comissão norte-rio-grandense 


\begin{tabular}{|c|c|}
\hline MINAS GERAIS & $\begin{array}{l}\text { Escola Normal Modelo } \\
\text { Grupo Escolar Barão de Macaúba } \\
\text { Grupo Escolar Barão do Rio Branco } \\
\text { Escola Infantil Bueno Brandão } \\
\text { Instituto João Pinheiro }\end{array}$ \\
\hline RIO DE JANEIRO & $\begin{array}{l}\text { Escola Normal de Niterói } \\
\text { Escola Profissional Feminina } \\
\text { Escola Normal do Distrito Federal } \\
\text { Escola Primária Bárbara Ottoni } \\
\text { Escola Christiano B. Ottoni } \\
\text { Escola Epitácio Pessoa } \\
\text { Escola Primária José Pedro Varela } \\
\text { Escola Profissional Paulo de Frontin }\end{array}$ \\
\hline ESPÍRITO SANTO & $\begin{array}{l}\text { Escola Normal do Espírito Santo } \\
\text { Grupo Escolar Gomes Cardim } \\
\text { Colégio Nossa Senhora do Carmo }\end{array}$ \\
\hline
\end{tabular}

Fonte: elaborado pelas autoras a partir de informações contidas no relatório de viagem “Da organização do ensino normal, profissional e primário no sul do Brasil e no Rio da Prata" (1923).

A partir das informações sistematizadas inferimos sobre quão amplas foram as ambições do educador na realização de seu trânsito. O vasto percurso, bem como os registros dele derivados, nos permitiriam várias possibilidades para discussões e análises acerca da docência a partir das interpretações por ele construídas. No entanto, para esta pesquisa, nos dedicamos a percorrer e examinar seu olhar sobre o que ele mesmo categorizou enquanto educação profissional.

Embora Nestor Lima tenha observado diferentes espaços de formação, a exemplo das Escolas Normais, Escolas de Aplicação, Escolas de Prática e Faculdade de Pedologia, é válido destacar a distinção por ele estabelecida e que se expressa desde o título do relatório, quando sinaliza a divisão entre os ensinos normal, profissional e primário. Essa lógica estende-se também à organização das seções que abordam separadamente as instituições de formação docente, de ensino profissional e de ensino primário. Sua escrita é organizada segundo essa categorização e perceber tal aspecto nos convida a refletir tanto sobre seu ponto de vista, como a respeito do entendimento coletivo do que caracterizava uma instituição de educação profissional. 
Depois de percorrer pelo cenário educacional uruguaio, partiu às 10 horas da noite do dia 09 de maio de 1923, a bordo do vapor fluvial "Ciudad de Buenos Ayres", chegando em seu próximo destino, a Argentina, às 08 horas da manhã do dia seguinte. Em suas considerações iniciais sobre Buenos Aires, tece uma escrita permeada de impressões pessoais, ao afirmar que um dos mais antigos anseios de sua carreira no ensino era conhecer de perto o adiantado centro de cultura que era a capital desse país, visto que se dizia "acostumado a admirar os seus progressos, nos diversos aspectos da sua civilização aprimorada, desejava desde muito pôr-me em contato com aquele povo irmão e com seus institutos pedagógicos” (LIMA, 1923, p. 34). Suas primeiras observações relacionadas à educação profissional registram-se através da exposição acerca das Escuelas Complementarias ou Continuativas.

Na parte referente ao ensino profissional, dirigi minhas vistas para um modelo de ensino profissional, que a Argentina ensaiou durante alguns annos e agora realiza vantajosamente, com uma amplitude animadora. Refiro-me aos cursos complementares que, sem serem Escolas Insdustriaes, todavia, fornecem preparação profissional, em horários apropriados e nos edificios das escolas primarias communs (LIMA, 1923, p. 45, grifos do autor).

Tais escolas eram voltadas aos jovens e adultos que por motivos diversos não conseguiram frequentar o ensino primário ou secundário, cumprindo com a legislação educacional do período em relação ao acesso ao mínimo de instrução exigido. No acervo da Biblioteca Nacional de Maestras y Maestros ${ }^{4}$, tivemos acesso ao texto da Lei $\mathrm{n}^{\mathrm{o}}$ 1420 promulgada em 08 de julho de 1884, durante a presidência de Julio Argentino Roca, que em seu artigo 12 versava sobre os ensinamentos rudimentares de responsabilidade das escolas ambulantes e de adultos, dentre os quais figuravam os conhecimentos acerca de leitura, escrita e as quatro operações da matemática, além do ensino de noções de língua materna, moral e urbanidade. Além desses, eram acentuados também os ensinamentos de história e geografia nacional, bem como o estudo da Constituição Federal Argentina, tudo em conexão com os campos de trabalhos dos(as) estudantes que frequentavam essas escolas (ARGENTINA, 1884). A Lei que reestruturou a educação nacional argentina ainda no século XIX, teve como princípios essenciais: obrigatoriedade, gratuidade, gradualidade e neutralidade

\footnotetext{
${ }^{4}$ Disponível em: http://www.bnm.me.gov.ar/. Acesso em: 12 jul. 2021.
} 
religiosa e a reorganização das instituições e processos educativos enquanto projeto de reconfiguração da nação. De acordo com Zaidenwerg, (2009, p. 5):

Ao longo de intensas sessões parlamentares se discutia um sistema educativo, o que estava em jogo, no entanto, era o modelo de estado, de nação e finalmente de sociedade que se pretendia consolidar. Tanto os grupos dirigentes como os intelectuais que participaram na definição do dito sistema sabiam da importância que a dita lei comportava, o que significaria a máxima de formar ao cidadão, na integração dos distintos grupos sociais, culturais e étnicos, na criação de uma identidade nacional e, não menos importante, na legitimação do poder do Estado.

Corroboramos com a compreensão do autor ao passo em que observamos que, ao descrever os princípios seguidos pelas Escuelas Complementarias, Nestor Lima enumera um total de 7 "propósitos especiais" que norteavam o ensino oferecido por essas instituições. Particularmente, versavam não somente sobre a ampliação e aperfeiçoamento das aptidões técnicas dos estudantes para o trabalho, como também apontavam para questões mais amplas de construção social, atribuindo finalidades econômicas e morais a partir do gênero feminino ou masculino que era educado(a) pela proposta da referida escola. Os artigos $5^{\circ}$ e $6^{\circ}$ compreendidos entre os propósitos específicos apontavam a necessidade de: "50 - Inculcar na mulher princípios fundamentaes de Eugenia, com fim de diminuir a morbilidade infantil e propender para o melhoramento da raça" $\mathrm{e}^{\text {" } 60}$ Melhorar a cultura esthetica, o gosto artistico que, nas applicações ao lar, tornam agradavel o ambiente, cimentando a moral e a virtude" (LIMA, 1923, p. 46).

O educador interpretou a docência nesses espaços como um grandioso empreendimento pedagógico de relevante valor educativo. Ao analisarmos sua leitura sobre os referidos lugares e o modelo de ensino que lá desenvolvia-se, deduzimos que sua compreensão sobre a docência na educação profissional apontava para uma prática formativa que se resumia ao campo das atividades laborais com pontuais elementos civilizatórios. Ademais, fez menção ao grande espectro de alcance do ensino complementar profissional, regulamentado pelo Conselho Nacional de

\footnotetext{
${ }^{5}$ Eugenia: pseudociência embasada na ideia de purificar a raça e aperfeiçoar o homem a cada nova geração. As origens do pensamento eugênico moderno têm raízes no período do lançamento do livro de Charles Darwin, Origem das Espécies. Sobre este assunto consultar: Diwan (2015).
} 
Educação destacando que, até o ano de 1923, existiam na capital de Buenos Aires 56 cursos dessa natureza e que reuniam o total de 40.000 alunos matriculados.

De acordo com Paredes e Pochulu (2005), com a criação oficial de 56 escolas complementares em 1922 o poder público executa de modo definitivo a vinculação entre educação e trabalho através da perspectiva de formação profissional de trabalhadores. Nesse momento, quando as aludidas escolas haviam sido criadas, estava em pauta a discussão de questões relacionadas à docência e aos métodos em uso. A natureza da formação oferecida nas instituições profissionais correspondia diretamente ao perfil de docência que se perscrutava para atuação nesses espaços.

As disciplinas presentes nos programas de ensino apontam que não era suficiente apenas o saber empírico da atividade laboral, mas, havia também uma preocupação com os conhecimentos rudimentares sobre leitura, escrita e cálculos matemáticos, assim como com os métodos de ensino através dos quais os processos formativos se desenvolviam. Outro elemento que nos permite empreender esta compreensão é a criação da Associação Nacional de Professores Especiais de Escolas para Adultos, visto que essa iniciativa evidencia as especificidades circunscritas ao professorado atuante nas escolas de preparo profissional. Sobre este aspecto, na edição de 1922 do periódico El Monitor de la Educación Común, publicação oficial do Conselho Nacional de Educação da Argentina, encontramos o resumo de uma conferência ministrada para os professores das escolas de Roma em maio do mesmo ano, onde se destaca El problema del método (1922), que enfatizava a relação intrínseca entre os métodos de ensino com a atuação dos professores para a educação que se ambicionava ofertar:

[...] A alma moral reta, equilibrada, humana dos professores é, certamente, a exigência essencial, mas é a forma que necessita seu conteúdo: o método; como este, a sua vez, é condição fundamental que a ação educativa, mas é o conteúdo, que necessita de sua forma: a alma e a vontade moral do professor. Se se rompe essa unidade, se terá por um lado o professor empírico que toma o ensino como uma profissão qualquer, e por outro o utópico generoso, mas estéril (VIDARI, 1922, p. 274-275).

Sobre este aspecto, o texto de autoria de Miguel Alier (1925), adverte acerca dos cuidados necessários com as atuações docentes nas instituições supracitadas. Segundo ele, nesses cursos eram exigidos maiores esforços por parte dos professores 
e, dentre suas observações, evidencia a necessidade de procedimentos específicos para a educação de adultos. Assinala que usualmente as ações nesses espaços confundiamse com as que eram desenvolvidas nas escolas diurnas infantis. Responsabiliza, ainda, os professores quanto à economia de tempo e recursos para obtenção dos melhores resultados em seus trabalhos. Para o autor, não bastava que o Conselho Nacional tivesse criado as classes especiais de referência, programas de ensino adequados ou inspeção especializada do ramo; todo o restante da ação educativa deveria ser complementado com a ação pessoal de professores e diretores.

Em 14 de maio, Nestor Lima pôde conhecer um pouco mais do que se desenvolvia a esse respeito, ao visitar as Escuelas Complementarias Masculina e Feminina, localizadas na rua Entre-Rios, em Buenos Aires. Dentre as observações sobre a estrutura legislativa que subsidiava o funcionamento de tais escolas, o brasileiro estendeu seu olhar para a questão física e organizacional, destacando que tratava-se de um prédio novo e bem mobiliado, no qual aconteciam aulas das 06 às 19 horas da noite. Lá observou na seção feminina as classes: tecelagem em bastidor de tapetes, almofadas com algodão e lã; desenho, como disciplina preparatória para diferentes profissões; bordado, flores e chapéus; francês, inglês e castelhano.

A seção masculina, possuía o número de 700 alunos, com diferentes faixas etárias. Segundo o educador, havia estudantes com até 52 anos de idade frequentando os cursos de desenho geométrico (ornato e profissional); marcenaria $(s l o j d)^{6}$; datilografia; telegrafia e telefonia; francês, inglês e castelhano. Em sua descrição, Nestor Lima faz menção detalhada ao ensino de datilografia que baseava-se em um método prático que consistia no emprego dos dez dedos em um mapa que

\footnotetext{
${ }^{6}$ O Slojd é uma palavra de origem sueca que significa destro/hábil e inspirou um sistema educacional de origem finlandesa baseado no artesanato, sendo componente do projeto higienista que atrela instrução e trabalho. De acordo com Aprígio Câmara, educador norterio-grandense que publicou suas ideias na Revista $A$ Educação do Rio de Janeiro e depois na Revista Pedagogium, o slojd não é uma disciplina à parte; é a base mesma de todas as inferências do educando; é o meio de educação moral por excelência. O slojd é trabalho manual; slojd é a criança em ação, é o hábito de fazer, é a pedra do toque das habilidades, é a revelação das tendências anímicas que dormem no fundo do nosso ser. O slojd, na escola, como base de todas as lições, empregado pelo professor, tem esta qualidade, que nenhum outro processo de ensino é capaz de lograr - desperta vocações, e nos guia para o fim a que Deus nos criou (RIBEIRO, 2018).
} 
reproduziria o teclado de uma máquina, enquanto o professor ditava as palavras em voz alta e compassada. Conforme ocorria o ditado, os alunos aplicavam os dedos sobre as respectivas teclas. Ele descreve a iniciativa como um excelente método prático e afirma ter ouvido do professor que, a partir deste tipo de trabalho, estavam conseguindo em poucos dias verdadeiros prodígios no aprendizado da datilografia.

Os cursos complementares eram divididos em dois grupos, denominados Cultura Geral e Estética e Finalidade Técnica, onde, a partir do segmento cursado, era ministrado o conjunto de disciplinas que lhes eram correspondentes. Essas matérias se agrupavam de acordo com as necessidades de cada aluno. No primeiro grupo, respectivamente, figuravam: matemática, idioma nacional, história argentina, geografia econômica argentina, música (teoria, solfejo e canto), desenho de ilustrações e aplicado às artes domésticas e ortofonia. No segundo, além dos já citados, os educandos tinham acesso aos aprendizados sobre: aritmética comercial, correspondência comercial, guarda, conservação de livros e caligrafia, datilografia, idiomas (francês, inglês, italiano etc.), desenho industrial, eletrotécnica (radiotelegrafia e radiotelefonia), química industrial, corte, confecção, higiene, puericultura e primeiros auxílios.

Analisamos que no rol das disciplinas circunscritas na categoria Cultura Geral e Estética, figuram saberes mais gerais que poderiam servir às atividades da vida cotidiana, ou seja, de cunho propedêutico para auxiliar na instrução e no exercício de outras profissões que não estivessem diretamente ligadas à educação técnica oferecida pelas Escuelas Complementarias ou Continuativas. O grupo de componentes compreendidos no segmento Finalidade Técnica atende às especificidades requeridas pelo mercado de trabalho, oferecendo preparo técnico específico para as distintas possibilidades de atuações profissionais. Outro elemento que consideramos relevante é que o ensino de idiomas se amplia no segundo grupo para além do idioma nacional, ofertado no primeiro. Após cursar a classe de disciplinas correspondente à formação profissional almejada, os alunos recebiam um certificado de frequência e, por fim, o Inspetor Técnico lhes fornecia um outro de aptidão na especialidade cursada.

Nestor Lima assinala que esses grupos despertavam “[...] muito interesse no povo e as autoridades argentinas estão confiantes no seu grande valor educativo" (LIMA, 1923, p. 48-49). Sua afirmação nos chama a atenção, pois, analisando os dados 
que correspondem ao público atendido, horário noturno de funcionamento, alto número de alunos matriculados e formação profissionalizante oferecida, inferimos que tratavam-se de cursos provavelmente voltados ao atendimento das classes populares que, pela própria necessidade de sustento, afastaram-se dos bancos escolares ainda na infância e, na vida adulta, buscavam qualificação no contraturno de suas atividades laborais para a profissionalização em algum segmento que possibilitasse a inserção no mercado de trabalho.

Finalizando sua visita à capital argentina, destaca que não teve "[...] ensejo de visitar a Escuela Industrial de la Nacion que, tanto pela sua finalidade industrial, como pela sua custosa organização material, seria inadaptável às nossas condições. Estou, porém, informado de sua efficiencia extraordinaria e do seu valor profissional" (LIMA, 1923, p. 49, grifos do autor). Sua afirmação corrobora com o nosso entendimento de circulação de modelos educativos uma vez que compreendendo a inviabilidade de aplicação de determinado projeto em seu estado de origem, abandona a possibilidade de visita à outra instituição. A viagem possui objetivos de observação do que considerava modelar e viável de execução em solo brasileiro, a partir dos empréstimos de ideias e práticas educativas que orientariam as ações do dirigente educacional no retorno à sua terra natal.

No trabalho com relatório de viagem, esquadrinhamos os entendimentos de Nestor dos Santos Lima sobre a docência não apenas a partir do que apresenta em sua escrita mas, também, por meio dos indícios presentes nas situações que optou por narrar. A partir do que enaltece, percebemos sua predileção pelos métodos que evidenciam a dimensão mais prática do ensino, bem como sua crença na formação para o trabalho como precursora do progresso nacional a partir da educação. 


\section{De volta ao solo pátrio: instituições profissionais no sudeste brasileiro}

Em 17 de maio de 1923, o educador despediu-se das autoridades argentinas, embarcando novamente no transatlântico "Cap. Polonio", com destino ao Rio de Janeiro. Após um período de descanso, seguiu em direção ao estado de São Paulo, lá chegando em 29 de maio. Suas primeiras informações acerca do ensino paulista registram a existência de 1963 instituições, distribuídas entre: Grupos Escolares (199); Escolas Reunidas (261); Escolas Isoladas (1486); Escolas Normais (10); Escolas Profissionais (4); e Ginásios Secundários (3).

Dentre as quatro instituições profissionais existentes, Nestor Lima visitou duas: a Escola Profissional Feminina e a Escola Profissional Masculina. No tocante à primeira, respectivamente, inicia suas observações apontando a razoabilidade das instalações arquitetônicas para o desenvolvimento de bordado, confecções, flores, além das aulas de português, aritmética e economia doméstica. As demais pontuações sobre a educação feminina no espaço mencionado são superficiais e versam apenas sobre as muitas alunas, os trabalhos já concluídos e as encomendas que possuíam altos preços para venda. Afirma ser um trabalho efetivo que tem alcançado um bom nível de funcionamento e atribui o sucesso da instituição ao educador que a dirige, professor João Lourenço Rodrigues.

Percebemos mais alguns aspectos com relação à educação feminina, quando no relatório são descritos os aprendizados nas escolas que recebiam ambos os sexos, masculino e feminino. Havia, simultaneamente, aulas de desenho profissional para os dois sexos; artes plásticas para as masculinas e, para as femininas, economia doméstica; puericultura; lavagem; e engomado. Dentre as ofertas, estavam circunscritos os ensinos de datilografia e estenografia; laticínios e noções de veterinária; fotografia; contabilidade em geral; horticultura e jardinagem; avicultura e agricultura; barbearia, cabelaria, pedicure e manicure.

$\mathrm{Na}$ tarde de 06 de junho, segue em direção à Escola Profissional Masculina, a qual dedica três páginas de seu relatório. Diferente da instituição destinada às mulheres, a escola masculina funcionava em um prédio que foi alvo de elogios por parte do educador potiguar. Verifica que a mesma possui excelentes instalações e 
também descreve os cursos que a legislação da educação contemplava em termos de oferta, dentre os quais figuravam: mecânica, marcenaria, pinturas, eletrotécnica, funilaria, motoristas mecânicos, marmoraria, tapeçaria e empalhação, gravação e zincografia, relojoaria, ourivesaria, pesca, douração, niquelagem e alfaiataria.

Após uma minuciosa descrição das ofertas e trabalhos desenvolvidos, apresenta sua opinião sobre os processos educativos observados acentuando que "[...] tudo isto indica, a meu vêr, um superior esforço educativo, uma verdadeira comprehensão do papel do trabalho manual, como fator da educação do espirito" (LIMA, 1923, p. 68). Esta afirmação permite-nos ratificar que o seu entendimento acerca das relações entre trabalho e educação, alinhava-se com a compreensão desta junção enquanto possibilidade formativa civilizatória.

Ao descrever a escola masculina, Nestor Lima parece conduzir o leitor juntamente consigo, através de sua escrita. Fez questão de detalhar seu percurso no interior do prédio e explicitar por completo o que visitou, classe por classe, departamento por departamento, instalação por instalação, observando e tendo acesso a cada peça que era produzida nesse espaço de aprendizados laborais. Seu encantamento com tal iniciativa é explícito, sobretudo, ao tecer comentários sobre o investimento nesse projeto educativo, destacando a relevância do trabalho manual como precursor da educação do espírito.

Analisamos que crescia nos dois países o mesmo movimento de valorização da formação profissional. Tanto as iniciativas argentinas, quanto o interesse por parte do dirigente brasileiro em empreender uma viagem para conhecer tais projetos educativos, apontam para uma demanda que se impunha naquele contexto histórico dos anos iniciais do século XX. Nesse sentido, dialogamos com De La Fare (2010, p. 14) ao afirmar que:

Um dos eixos centrais dos debates da época era a inclusão dos espaços escolares de ensino de manual e conhecimentos associados à formação para o trabalho, assim como o papel da sociedade civil na gestão das instituições escolares por meio das sociedades populares de educação. Em meados da década de 1920, foi encerrado um ciclo nessas discussões, com a incorporação da formação para o trabalho [...] considerada como uma resposta orgânica às demandas da sociedade civil. 
A partir das interpretações do viajante acerca das cenas experimentadas no cotidiano da escola masculina paulista, identificamos alguns aspectos que nos chamam à reflexão acerca das práticas docentes desenvolvidas naquele espaço. Ao descrever os trabalhos da turma de aprendizes de mecânica, menciona um jovem de 13 anos de idade responsável pelo quadro de chaves da oficina, outro em idade próxima, um eletricista de 15 anos que instalava lâmpadas pelas galerias: "[...] chamou-o o diretor e falou-lhe. Mas, o aprendiz tombou à direita trez ou quatro passos, como si desaprumado, e quase à rectaguarda do seu interlocutor, é que poude responder às perguntas. Era um anormal que o trabalho aproveitou e corrigiu" (LIMA, 1923, p. 68). Com os detalhes de sua narrativa, inferimos que o ensino se destinava aos jovens que não tiveram acesso à escolaridade regular e que a docência desenvolvida nesses espaços era compreendida como a possibilidade de "aproveitar" e "corrigir" pessoas que, por alguma deficiência física ou intelectual, não poderiam ser inseridas em outras atividades laborais.

Em sua bagagem de volta, trouxe consigo cópias de Programas de Ensino e Regimentos Internos Escolares e, ao final de sua passagem por São Paulo, fez uma observação acerca da docência ali desenvolvida. Asseverava que os professores paulistas não eram meros reprodutores das diretrizes oficiais, visto que em suas ações, criavam, modificavam e/ou adaptavam processos de ensino ou aspectos metodológicos originais, tornando-se assim, merecedores de estímulos e investimentos financeiros. Nestor Lima avaliou o professorado paulista como didaticamente autônomo, o que, segundo ele, os educadores do Rio Grande do Norte ainda não o eram.

Em 11 de junho, continuou a viagem com destino a Belo Horizonte. Três dias após visitar escolas na capital mineira, seguiu de carro na manhã de 14 de junho em direção a um espaço que já almejara visitar, o Instituto João Pinheiro. Lá, foram recebidos pelo suíço Ottoson, diretor interino, durante a ausência de Leon Renault, diretor efetivo. Sobre este espaço, escreveu o viajante:

Era meu principal intento ao visitar Bello Horizonte, inspeccionar de visu esta afamada instituição que o genio pratico e o largo descortino do grande presidente que foi o dr. João Pinheiro da Silva, logrigára com a creação da fazenda "Gamelleira" e que o esforço patriótico do coronel Bueno Brandão desdobrou e integrou no estebelecimento modelar, que hoje guarda o nome do primeiro, o qual é destinado 
ao aprendizado agricola e zootechnico dos meninos que a sorte não favoreceu, ou eram presas da vadiagem, como antecipação do crime e da detenção (LIMA, 1923, p. 85 , grifos do autor).

Segundo Faria Filho (1997, p. 104), o patrono dessa instituição, João Pinheiro, foi um “industrial e político mineiro, [...] que introduziu a organização dos grupos escolares, ao mesmo tempo, deu um grande incentivo ao ensino de caráter mais prático e de cunho semi-profissionalizante". Tal edificação possuía referências que variavam entre teóricos da Escola Nova e do Direito Criminal e pretendia criar um protótipo de estrutura modelar de sociedade em miniatura. De acordo com Nestor dos Santos Lima (1923), a organização era análoga a de um país e os pavilhões constituíam estados de uma república. Cada quarto era um município, sob a responsabilidade de seus ocupantes e, no corrente ano da visita, residia lá um número de 120 meninos que tinham acesso ao dormitório, refeitório, aulas, cinema, banda de música e instrução militar.

No ano de 1909 ocorreu a fundação do Instituto João Pinheiro por parte do governo de Minas Gerais, projeto que advinha das elites mineiras e que tinha como proposta central a recepção de crianças entre 08 e 12 anos que provinham de situação de abandono ou vulnerabilidade socioeconômica. O projeto atribuía centralidade à educação moral e cívica dos aprendizes, visando antever a marginalização desse público que, desprovido de educação e condições materiais, poderia futuramente representar riscos à segurança social.

Durante o mandato do governador Júlio Bueno Brandão (1910-1914), o ensino agrícola mineiro foi regulamentado e passou a ser regido pelo Decreto no 3356 de 11 de novembro de 1911, funcionando de acordo com a organização de três grupos centrais: o primário, ministrado nos grupos escolares; o ambulante, feito nas fazendas particulares, e o médio, desenvolvido nas fazendas modelos e fazendas subvencionadas. Além do trabalho agrícola, existiam os cursos de leitura, língua pátria, aritmética, geografia, geometria, canto, música, desenho, história do Brasil, história natural, noções de formas, física e química e trabalhos manuais.

No site do Arquivo Público Mineiro (APM) ${ }^{7}$ tivemos acesso a um rico acervo iconográfico. Dentre os materiais disponibilizados, constam fotografias do Instituto

\footnotetext{
${ }^{7}$ Disponível em: http://www.siaapm.cultura.mg.gov.br/. Acesso em: 25 jul. 2021.
} 
João Pinheiro, visitado por Nestor dos Santos Lima e, a partir das imagens, nos é possível maior aproximação com o cenário descrito pelo educador em seu relatório. O espaço estava situado no alto da colina e, além da casa do diretor e da administração, constavam quatro pavilhões intitulados: Bias Fortes, Bueno Brandão, Mendes Pimentel e Arthur Bernardes, cada um deles era independente sob todos os pontos de vista.

Figura 1 - Vista panorâmica do Instituto João Pinheiro

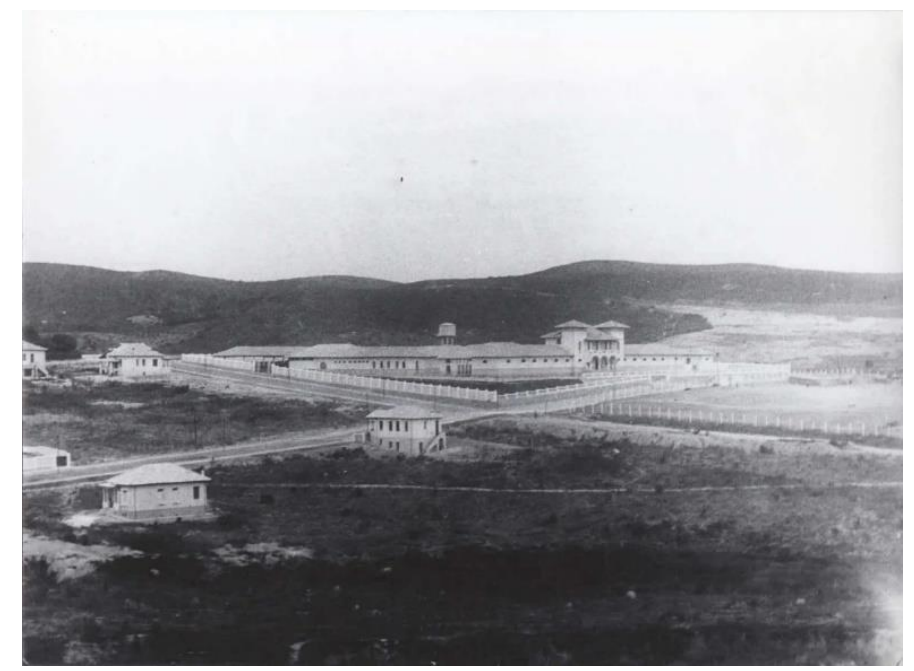

Fonte: Acervo do Arquivo Público Mineiro/APM (1920 - 1930)8.

Dentre as interpretações de Nestor Lima, a educação para a vida do trabalho e o treinamento moral e cívico dos alunos por meio das chamadas repúblicas tornavam os aprendizes capazes de bastarem a si próprios "realizando quase uma das maiores e mais bellas conquistas contemporanea: a escola nova" (LIMA, 1923, p. 87, grifos do autor). É mister refletir sobre a relação que o educador estabelece entre o ideário escolanovista e sua premissa de renovação pedagógica, com a educação desenvolvida no Instituto João Pinheiro, voltada sobretudo à instrução, qualificação e civilização, conforme discute Faria Filho (1997, p. 104):

A escola se racionalizava justamente para dar conta de suas tarefas cada vez mais amplas e complexas. A escola se racionalizava justamente porque tinha como finalidade última racionalizar o conjunto social. Deste processo a racionalização, a divisão e o controle do trabalho docente são elementos fundamentais, mas não

\footnotetext{
8 No site do Arquivo Público Mineiro o período de 1920-1930 é apresentado como referência à provável data do registro. Sobre este assunto consultar: http://www.siaapm.cultura.mg.gov.br/modules/fotografico_docs/photo.php?lid=29214. Acesso em: 25 jul. 2021.
} 
exclusivos. Relacionada a este processo está, também, a crescente defesa de que a escola passasse a dar uma centralidade ao ensino professional.

É notável que a educação pelo e para o trabalho desenvolvia-se numa perspectiva civilizatória. Sobre este aspecto, Faria Filho (1997) ao discutir sobre as transformações pelas quais passava a escola primária nos anos iniciais do século XX, sobretudo quanto à sua função social, elucida que estas mudanças impactaram também a docência exercida nesses espaços. A relação intrínseca da escola com o mundo do trabalho influenciava na produção de outra identidade docente, a identificação do professor(a) como trabalhador(a), desse modo, a tríade do ler, escrever e contar, ofereceu lugar ao modelo de instrução que propunha educar o povo pelo e para o trabalho. As aspirações que motivaram as idas de Nestor Lima em busca de conhecer o funcionamento dos espaços que ele categorizou nos seus escritos como sendo de educação profissional, denotam o interesse mais amplo de formação em consonância com o projeto de país que ora se desenvolvia. Sua visita a Belo Horizonte nos parece ter sido uma das mais extensas, visto que esse trecho consumiu quase um mês de seu itinerário.

Dando seguimento à sua jornada pedagógica, chegou ao Rio de Janeiro em 5 de julho, mas, antes de visitar a capital federal, passou pela cidade de Niterói para acompanhar os trabalhos desenvolvidos na Escola Profissional Feminina, dirigida pela professora Aurélia Quaresma e vinculada ao Ministério da Agricultura. Destacou que essa visita se fez possível pelo seu antigo conhecimento com Miss Leora James que desempenhava as funções de inspetora geral das escolas profissionais para mulheres. Segundo Nestor Lima, diferente da Escola Profissional Feminina que observou em São Paulo, com uma estrutura física não condizente com a alta frequência de alunas e volumoso trabalho feito, as instalações da Escola Profissional Feminina no Rio de Janeiro eram excelentes, em prédio com largas proporções. No entanto, as instalações ainda eram incipientes ao funcionamento das aulas de costura, lavanderia, desenho, línguas, geografia e aritmética.

$\mathrm{Na}$ capital federal, Nestor Lima visitou o último espaço de educação para o trabalho descrito no relatório, a Escola Profissional Paulo de Frontin, criada em 1919. Dentre as atividades aprendidas nessa instituição também direcionada ao público 
feminino, aponta que o espaço possuía “[...] cursos de desenho, para várias applicações, officinas de flôres, chapéos, bordados e vestidos. Percorremos interessadamente o curso de desenho, pelas secções de flores, chapéos, vestidos, etc, como preparatórios do trabalho das oficinas" (LIMA, 1923, p. 107). De acordo com Bonato (2001, p. 1), essas escolas foram mantidas pelo poder municipal e tinham a finalidade de instruir as moças pobres, pois “[...] eram responsáveis pelo ensino profissional, comercial e doméstico, objetivando formar moças prendadas, para o lar e para o trabalho, em caso de necessidade". Ao citar o então Diretor Geral da Instrução Pública do Distrito Federal, Antonio Carneiro Leão, destaca que o curso era excessivamente procurado e que entre 1921 e 1925, aproximadamente 100 moças o concluíram e quase todas encontravam-se empregadas em suas respectivas profissões.

Quanto às atividades observadas, Nestor Lima destacou que pôde presenciar as moças fazendo exercícios de ambidestria, desenhando círculos e figuras à giz, com a utilização das duas mãos. "Ali executavam-se modelos de desenho colorido; além, as próprias alumnas creavam modelos de vestidos, chapéos e bordados, para depois executarem nas oficinas" (LIMA, 1923, p. 107). Finalizando sua visita, esteve nas oficinas conhecendo as confecções de flores e de chapéus. Ao final do registro de suas observações, faz referência ao destaque dos trabalhos produzidos pela escola, apresentados e vendidos no Pavilhão do Distrito Federal, na ocorrência da Exposição do Centenário, o que proporcionou à escola a obtenção de consideráveis recompensas financeiras.

A partir das visitas e relatos do viajante norte-rio-grandense, observamos que a educação feminina, inclusive nos institutos profissionais, era comprometida por diferentes aspectos, fossem eles financeiros, arquitetônicos, ou mesmo de pessoal docente nessas instituições. Avaliamos que nos anos iniciais do século XX ainda era preambular a presença feminina em muitas das atividades formais de trabalho requeridas no referido contexto histórico.

\section{Considerações finais}

No retorno à sua terra Natal, Nestor dos Santos Lima promoveu a organização da estrutura administrativa da educação norte-rio-grandense com a criação do 
Departamento de Educação (1924), em substituição à Diretoria Geral da Instrução Pública, ao qual eram subordinadas as Escolas Profissionais. O que se observam são aspectos estruturantes em relação aos cursos que tinham um caráter propedêutico humanístico em sua estrutura e um destaque ao ofício em formação.

Desse modo, seja na Argentina ou no Brasil, há semelhanças em relação às aspirações para a educação profissional e suas instituições. De igual modo, nota-se uma convergência no que tange ao perfil dos docentes em atuação. Constatamos que era requerido aos corpos docentes das instituições não apenas o conhecimento prático da profissão a ser desenvolvida, mas também os saberes necessários ao ensino de idiomas nacionais e estrangeiros, como é o exemplo das Escuelas Complementarias na oferta de idioma nacional, bem como francês, inglês, castelhano e italiano nas escolas masculinas e femininas. No Brasil, como é exemplificado no caso do Instituto João Pinheiro, além das atividades laborais agrícolas, eram previstos os ensinos de língua pátria, aritmética, geografia, geometria, canto, música, desenho, história do Brasil, história natural, noções de formas, física e química.

É válido destacar que a qualificação em um ofício era procurada pelos cidadãos em ambos os países e suas finalidades se ampliaram ao longo da segunda década do século XX, desvinculando-se da ideia de prover os "desfavorecidos da sorte" impressa na década anterior, principalmente no Brasil, e corroborando a necessária aquisição do conhecimento e prática do ofício, promovendo a elevação do nível moral e intelectual do operário, com alargamento da visão técnica e artística. Nesse sentido, as visitas comissionadas pelo professor Nestor dos Santos Lima e seu olhar para as instituições profissionais estrangeiras e nacionais, buscavam conferir cientificidade e significação social às formações para o ofício no país, com vistas a promover o progresso técnico nas oficinas e nas indústrias nacionais.

\section{Referências}

ALIER, M. Algunas observaciones: los cursos complementarios en las escuelas de adultos. El Monitor de la Educación Común: órgano del consejo nacional de educación, n. 597, p. 312315, 1925. Disponível em: http://www.bnm.me.gov.ar/giga1/monitor/monitor/597.pdf. Acesso em: 25 jul. 2021. 
ARGENTINA. Ley 1420 de 08 julio 1884. Ley reglamentando la Educación Común. Disponível em: http://www.bnm.me.gov.ar/giga1/normas/5421.pdf. Acesso em: 21 jul. 2021.

BARROS, J. D. Fontes Históricas: introdução aos seus usos historiográficos. Petrópolis: Editora Vozes, 2019.

BONATO, N. M. da C. Uma escola de formação profissional para o sexo feminino no Distrito Federal: a Escola Profissional Paulo Frontin (1919). In: REUNIÃO ANUAL DA ANPED, 24., 2001, Caxambu. Anais de Reuniões Cientificas Nacionais da ANPEd. [S.1.]: ANPED, 2001. p. 1-8. Disponível em: https://anped.org.br/biblioteca/item/uma-escolade-formacao-profissional-para-o-sexo-feminino-no-distrito-federal-escola. Acesso em: 25 jul. 2021.

CARDOSO, S. de F.; MORAES, D. Z. Viajar é inventar o futuro: narrativas de formação e o ideário educacional brasileiro nos diários e relatório de Anísio Teixeira em viagem à Europa e aos Estados Unidos (1925-1927). Jundiaí: Paco Editorial, 2014.

CATANI, D. B. Escrever e comparar-se, mapear e apropriar-se: questões da pesquisa em História da Educação. In: GATTI JÚNIOR, D.; PINTASSILGO, J. Percursos e desafios da pesquisa e do ensino de História da Educação. Uberlândia: UFU, 2007. p. 165-182.

CHARTIER, R. A bistória cultural entre práticas e representações. Rio de Janeiro: Editora Bertrand, 1990.

CIAVATTA, M. Memória e temporalidades do trabalho e da educação. Rio de Janeiro: Lamparina: Faperj, 2007.

CIAVATTA, M. Mediações históricas de trabalho e educação: gênese e disputas na formação dos trabalhadores (Rio de Janeiro, 1930-60). Rio de Janeiro: Lamparina, 2009.

COSTA, R. H. R. da. A imprensa cotidiana no periodo de 1889-1930 na cidade do Natal do Rio Grande do Norte. Orientador: Helder Nascimento Viana. 2005. 52f. Monografia (Graduação em História) - Centro de Ciências Humanas, Letras e Artes, Universidade Federal do Rio Grande do Norte, Natal, 2005.

CUNHA, L. A. O ensino de ofícios nos primórdios da industrialização. 2. ed. São Paulo: Unesp; Brasília: Flacso, 2005.

DE LA FARE, M. Principales ideas, discusiones y producciones en Educación de Jóvenes y Adultos en Argentina: aportes para una reconstrucción histórica. 1. ed. Buenos Aires: Ministerio de Educación de la Nación; DiNIECE, 2010.

DIWAN, P. Raça Pura: uma História da Eugenia no Brasil e no Mundo. São Paulo: Contexto, 2015.

FARIA FILHO, L. M. de. Instruir, Civilizar e qualificar: representações sobre o trabalho na cultura escolar. Trabalho e Educação, Belo Horizonte, n. 1, p. 100-112, fev./jul. 1997.

GONDRA, J. G. Exercício de comparação: uma normalista da corte na Europa. In: MIGNOT, A. C. V.; GONDRA, J. Viagens pedagógicas. São Paulo: Cortez, 2007. p. 65-89. 
LIMA, N. dos S. Melhoramentos técnicos do ensino primário e normal. Natal: Typ. Do Instituto, 1913.

LIMA, N. dos S. Da organização do ensino normal, profissional e primário no sul do Brasil e no Rio da Prata. Natal: Typ. d'A República, 1923.

PAREDES, S. M.; POCHULU, M. D. La institucionalización de la Educación de Adultos en la Argentina. Revista Iberoamericana de Educación, v. 36, n. 8, p. 1-12, 2005.

RIBEIRO, M. F. The Slójd and the moral education of the young. Research, Society and Development, v. 7, n. 10, p. 1-12, 2018.

RIBEIRO, M. F. Revista Pedagogium: a associação de professores em ação pelo projeto educativo da Escola Nova no RN (1920-1932). Orientadora: Maria Inês Sucupira Stamatto. 2020. 207f. Tese (Doutorado em Educação) — Centro de Educação, Universidade Federal do Rio Grande do Norte, Natal, 2020.

RIONDET, X.; HOFSTETTER, R.; GO, H. L. Les acteurs de l'Éducation nouvelle au XXè siècle. Grenoble: Presses Universitaires de Grenoble, 2018.

ROLDÁN VERA, E.; FUCHS, E. O transnacional na história da educação. Trad. Alexandre Ribeiro e Silva, Ana Carolina de Carvalho Guimarães e Diana Gonçalves Vidal. Educação e Pesquisa, v. 47, p. 1-32, 2021.

STEPHANOU, M.; BASTOS, M. H. Histórias e Memórias da Educação no Brasil. Petrópolis: Vozes, 2018. v. III.

VIDAL, D. G.; FARIA FILHO, L. M. de. Reescrevendo a história do ensino primário: o centenário da lei de 1827 e as reformas Francisco Campos e Fernando de Azevedo. Educação e Pesquisa, v. 28, n. 1, p. 31-50, 2002.

VIDARI, G. El problema del método. El Monitor de la Educación Común: órgano del consejo nacional de educación, n. 597, p. 273-275, 1922. Disponível em: http://www.bnm.me.gov.ar/giga1/monitor/monitor/597.pdf. Acesso em: 25 jul. 2021.

ZAIDENWERG, C. El sistema educativo argentino. De cómo se construye una nación (1880-1930). In: JORNADAS INTERESCUELAS/DEPARTAMENTOS DE HISTORIA, 12., 2009, San Carlos de Bariloche. Actas... [S.l.: s.n.], 2009. p. 1-21. Disponível em: https://cdsa.aacademica.org/000-008/820. Acesso em: 25 jul. 2021.

RECEBIDO: $31 / 07 / 2021$ 